\title{
End of the Road for the Diesel Engine?
}

\section{Dear Reader,}

Whenever I talk to friends about the subject of diesel engines, it soon becomes clear just how great their uncertainty is. Even many of the die-hard diesel fans are now saying that they will choose a different type of engine when they get round to buying their next car. And if you ask them why, you hear words like driving ban and environment. The so-called diesel scandal and the recent summit on diesel engines also play a considerable role in exacerbating this uncertainty and strengthening this shift in consumer preference. For example, many are wondering why millions of dollars in fines and compensation have to be paid in the USA, whereas in Germany all that is required is a software update.

It is clear to anyone with some knowledge of engineering that the reaction to the diesel issue is exaggerated. Even in the off-highway sector, engine manufacturers have made great efforts over the past twenty years to significantly reduce exhaust emissions from diesel engines. Countless new technical solutions have been successfully launched onto the market on a wide scale during this time. Sales brochures are now full of technical terms like DOC for diesel oxidation catalyst, DPF for diesel particulate filter, EGR for exhaust gas recirculation and SCR for selective catalytic reduction. And there is no end in sight. 2019 will see the introduction of the even stricter Stage V emissions standard for diesel engines. It is to apply to all power output classes by 2020 .

And engine manufacturers are facing even more challenges alongside the need to comply with Stage V in a short time scale. This new standard also means that the engine markets in Europe and the USA are starting to diverge. There are as yet no plans in North America to introduce a Tier 5 standard.

It is not clear to me why the diesel engine is now falling into such disrepute in Europe of all places. After all, Europe has the world's strictest emission standards - and they are set to get even stricter. For example, the findings of two studies are to be presented to the European Commission by the end of 2018 and 2020, respectively, on the basis of which further decisions are to be made regarding the possible introduction of an EU Stage VI standard.

But in all of these discussions, one point should not be forgotten: in the mobile machine sector in particular, there is no real alternative to the diesel engines that are installed in most machines.
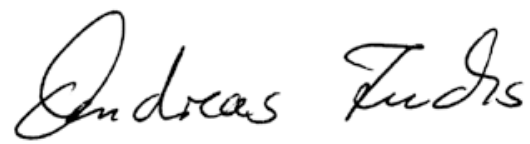

Andreas Fuchs

Chief Correspondent

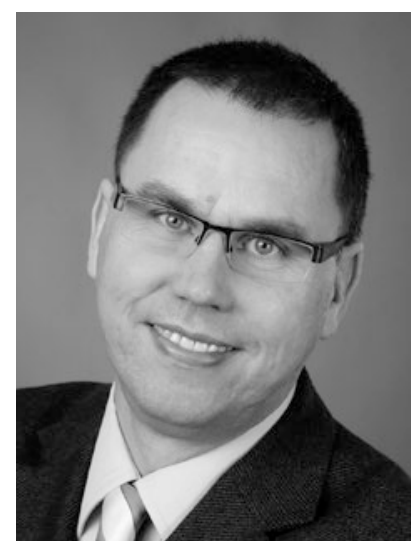

